\title{
Effect of intra and inter-personal factors on adolescents' energy intakes
}

\author{
A. S. Mohd Shahar, Z. Ibrahim and M. N. Mohd Taib \\ Department of Nutrition and Dietetics, Faculty of Medicine and Health Sciences, Universiti Putra Malaysia, \\ 43400 Serdang, Selangor, Malaysia
}

Adolescence is a crucial stage of development in human life and having adequate dietary intake plays an important role in the physical development and overall well-being. The dietary intake of adolescents is one of the major concerns in public health as there are growing evidences that link poor nutrition to elevated risks of obesity-related health problems. This cross-sectional study aimed to determine the effect of intra and inter-personal factors on energy intake of the adolescents in Hulu Langat District of Selangor, Malaysia.

A total of 457 adolescents aged 13-16 years from five selected schools were recruited through multistage cluster sampling. Self-administered questionnaires consisted on socio demographic background, intra and interpersonal factors were distributed. Intrapersonal factors were operationalised as eating behaviour and personality traits. Whereas interpersonal factors include parenting styles and social support. Eating behaviours were assessed using Three-Factor Eating Questionnaire-R18 ${ }^{(1)}$. TFEQ-R 18 has 18 -item which measures three types of eating behaviours; restrained eating, uncontrolled eating and emotional eating. Personality traits were obtained using Universiti Sains Malaysia (USM) Personality Inventory (USMaP-i) ${ }^{(2)}$. USMaP-i has 60 -item that measures respondents' personality which divided into extraversion, conscientiousness, agreeableness, neuroticism and openness to experience. Parenting styles were assessed through Parental Authority Questionnaire ${ }^{(3)}$, while social support was determined using Multidimensional Scale of Perceived Social Support (MSPSS) $)^{(4)}$.The current dietary intake was measured through 24-hour dietary recall. The estimated dietary intakes were computed in Nutritionist Pro software and the energy intakes were compared with Recommended Nutrient Intake (RNI) for adolescents.

The sample comprised of $84.2 \%$ Malays, $8.1 \%$ Chinese, $6.8 \%$ Indian, while $0.1 \%$ were from other ethnic groups. Distribution of the respondents according to age showed $30.0 \%$ aged 13 years old, while $33.9 \%$ and $36.1 \%$ aged 14 and 16 respectively. Energy intake of the respondents reached an average of $51.9 \%-62.4 \%$ of RNI. Hierarchical multiple linear regression (adjusted for age, sex and ethnicity) (Table 1) revealed that both intra and interpersonal factors contributed to the dietary intakes of adolescents. Adolescents with uncontrolled eating behaviour $(B=0.171, \mathrm{CI}$ : $3.95-11.85)$ and have significant support from family members $(\mathrm{B}=0.101, \mathrm{CI}$ : 7.20 21.40) were found to have strongest influence on their energy intakes. Nevertheless, those with conscientiousness personality trait $(B=-0.096, C I: 2.02-25.49)$ were more cautious in controlling their energy intakes.

Table 1. Hierarchical multiple regressionv* prediction the dietary intake from intra and interpersonal factors among adolescents

\begin{tabular}{lccc}
\hline Variables & $\begin{array}{c}\text { Standardized coefficient coefficient } \\
\text { Beta }\end{array}$ & $95 \% \mathrm{CI}$ & $\mathrm{R}^{2}$ \\
\hline Interpersonal factors: & & & \\
\hline Eating Behaviour-Uncontrolled eating & 0.171 & $3.95-11.85$ \\
Personality Traits-Conscientiousness & -0.096 & $2.02-25.49$ & 0.136 \\
Intrepersonal factors: & & & 0.106 \\
Parenting Style-Authoritarian father & 0.100 & $-6.77-9.32$ \\
Parenting Style-Authoritarian mother & -0.028 & $-10.71-5.24$ \\
Parenting Style-Permissive father & 0.005 & $-8.29-7.38$ \\
Social Support-Family support & 0.101 & $7.20-21.40$ \\
Social Support-Friend support & 0.91 & $-0.49-23.00$ \\
\hline
\end{tabular}

* Adjusted for age, sex and ethinicity, $\mathrm{R}^{2}=.136[\mathrm{~F}(15,441)=4.609]$

Energy consumption of adolescents could be influenced by both intra and interpersonal factors, which highlight a need to consider multiple approaches at individual, home and environment in planning and executing any health and nutrition intervention program.

1. Karlsson J, Persson LO, Sjostrom L, et al. (2000) Inter J of Obesity \& Related Met Dis 24, 1715-1725.

2. Muhd Saiful BY, Ahmad Fuad AR \& Abdul Rahman N (2010) The USM Personality Inventory (USMaP-i) Manual. Kelantan, Malaysia: KKMED Publications.

3. Reitman D, Rhode PC, Hupp SDA et al. (2002) J of Psych \& Behav Assess 24, 119-127.

4. Wongpakaran T, Wongpakaran N \& Ruktrakul R (2011) Clin Prac \& Epid in Mental Hlth 7, 161-166. 